\title{
Deficiência de boro na cultura do abacaxi 'Pérola'"
}

\author{
Susana Cristine SIEBENEICHLER², Pedro Henrique MONNERAT², José Accácio da SILVA ${ }^{4}$
}

\section{RESUMO}

Vinte plantas de abacaxi 'Pérola' foram cultivadas em vasos de plástico de $10 \mathrm{~L}$, em casa de vegetação, com o objetivo de caracterizar os sintomas visuais de deficiência de B nas plantas e nos frutos. Os vasos continham areia de rio lavada cinco vezes com água comum e depois duas vezes com água desionizada. Dez plantas foram irrigadas com solução completa e, de outras dez, o B foi suprimido da solução cinco meses após o plantio. As plantas apresentaram crescimento vegetativo normal e formaram frutos normais. Após a colheita dos frutos, acompanhou-se a formação das mudas do tipo rebento e rebentão basal, onde se observou que as plantas cultivadas sem B formaram mais mudas do tipo rebento do que as plantas cultivadas com B. Na formação das mudas do tipo rebentão basal, não se observou o efeito da supressão do B. No cultivo da plantasoca e em rebentões basais, cultivados em solução nutritiva sem B, observaram-se sintomas de deficiência de B somente no período reprodutivo. Os sintomas de deficiência de B se caracterizaram por: frutos deformados e menores, com formação de excrescência cortiçosa ou secreção de goma entre os frutilhos, rachaduras entre estes preenchidas com excrescência cortiçosa. As mudas tipo filhote formadas nas plantas-soca apresentaram folhas com falhas na borda e pontas secas.

PALAVRAS-CHAVE: Ananas comosus, fruticultura, mobilidade, deficiência mineral.

\section{Boron deficiency in pineapple 'Pérola'}

\section{ABSTRACT}

Twenty pineapple 'Pérola' plants were cultivated in 10L plastic pots in a greenhouse, with the objective of characterizing the visual symptoms of boron deficiency in the pineapple leaves and fruit. The pots contained river sand that was washed five times with common water and two times with deionized water. Ten plants were irrigated five months after planting with a complete nutrient solution and the other ten, without B in the solution. The plants presented regular vegetative growth and fruit formation. After the harvest of the fruit, the formation of shoot and suckers seedling types were accompanied, where it was possible to observe that plants were grown without B produced more seedling from the shoot type than from those ones grown with B. The formation of suckers was not affected by the suppression of B from the nutrient solution. Symptoms of boron deficiency were observed only in the fruiting period in plants in the second cycle of growth. Symptoms of B deficiency were characterized by deformed and smaller fruit, with formation of cork tissue or gum secretion among the fruitlets and cracks filled out with of cork tissue. Slip formed in second cycle plants had leaves with uneven borders and dry tips.

KEYWORDS: Annanas comosus, B retranslocation, B deficiency, horticulture.

\footnotetext{
${ }^{1}$ Trabalho extraído da tese de doutorado da primeira autora realizado na UENF. FAPERJ: PROC. No E-26/171.410/2000

${ }^{2}$ Eng. Agr. Dra. Produção Vegetal, Professora Adjunta no CAUG/UFT, Gurupi, TO. E-mail: susana@uft.edu.br

${ }^{3}$ Eng. Agr. PhD em Nutrição Mineral de Plantas. Professor Titular da UENF, Campos dos Goytacazes, RJ. E-mail: monnerat@uenf.br

${ }^{4}$ Eng. Quím. Técnico de Nível Médio da UENF, Campos dos Goytacazes, RJ. E-mail: jaccacio@uenf.br
} 


\section{INTRODUÇÃO}

Os solos da região Norte Fluminense, nos quais se cultiva o abacaxizeiro, são em geral arenosos, com pH ácido e estão sob regimes de chuvas desuniformes, ao longo do ano. Essas condiçōes favorecem a baixa disponibilidade de B para as plantas. Nesta região, a deficiência deste micronutriente já foi constatada em algumas culturas, como: maracujá, coco, rabanete e jiló.

Em geral, os sintomas visuais da deficiência de B caracterizam-se por deformação do fruto, queda de flores, não-vingamento de frutos, deformação de folhas novas e morte do meristema apical da planta, caules e pecíolos quebradiços (Epstein e Bloom, 2006). Em alguns frutos, também se observa a formação de excrescências cortiçosas (Marschner, 1995; Malavolta et al., 1997; Malézieux \& Bartholomew, 2003).

Para facilitar o entendimento as folhas de uma planta de abacaxi foram classificadas, sendo que a folha de referência para análise dos teores dos nutrientes é a folha " $D$ ", está é a folha mais velha das mais novas, ou seja, é a folha totalmente expandida e sua posição na planta forma um ângulo de $45^{\circ}$ com a superfície do solo.

Em abacaxizeiro, alguns sintomas foram descritos, mas, em sua maioria, são provenientes de experimentos realizados em outros países. Provavelmente, os resultados sejam provenientes da cultivar Smooth cayenne, a mais plantada no mundo. No Brasil, a cultivar mais plantada comercialmente é a Pérola. Assim sendo, talvez os sintomas exibidos pela 'Pérola', sob as condiçôes climáticas do Brasil, difiram dos já descritos na literatura.

As poucas informaçōes sobre os sintomas de deficiência de B em plantas e no fruto de abacaxi 'Pérola' motivaram a realização deste experimento. Assim, este trabalho objetivou caracterizar os sintomas visuais de deficiência de B em plantas e frutos dessa cultivar de abacaxi.

\section{MATERIAL E MÉTODOS}

\section{ENSAIO 1}

Vinte mudas de abacaxi 'Pérola' foram cultivadas desde outubro de 1999 em vasos plásticos (volume de $10 \mathrm{~L}$ ), em casa de vegetação do Setor de Nutrição Mineral de Plantas - Laboratório de Fitotecnia - CCTA/UENF. O substrato utilizado foi areia de rio lavada cinco vezes com água comum e, a seguir, duas vezes com água desionizada.

Desde outubro de 1999, as plantas foram irrigadas semanalmente com solução nutritiva completa contendo $\mathrm{Ca}\left(\mathrm{NO}_{3}\right)_{2}$. $4 \mathrm{H}_{2} \mathrm{O}: 2$ mmoles $\mathrm{L}^{-1} ; \mathrm{NH}_{4} \mathrm{NO}_{3}: 1$ mmoles $\mathrm{L}^{-1}$; $\mathrm{KH}_{2} \mathrm{PO}_{4}: 0,25$ mmoles $\mathrm{L}^{-1} ; \mathrm{KNO}_{3}: 4$ mmoles $\mathrm{L}^{-1}$; KCl: 50 $\mu$ moles $\mathrm{L}^{-1}$; MgSO4:1 mmoles L ${ }^{-1}$; Fe-EDTA: $40 \mu$ moles $\mathrm{L}^{-1}$; $\mathrm{MnSO}_{4} .2 \mathrm{H}_{2} \mathrm{O}: 5,0 \mu$ moles $\mathrm{L}^{-1} ; \mathrm{ZnSO}_{4} .7 \mathrm{H}_{2} \mathrm{O}: 2,0 \mu$ moles
$\mathrm{L}^{-1}$; CuSO .5H O: 0,5 $\mu$ moles L $\mathrm{L}^{-1}$; H BO : $25 \mu$ moles $\mathrm{L}^{-1} \mathrm{e}$ (NH ) $\mathrm{Mo}^{4} \mathrm{O}^{2} .4 \mathrm{H}$ O: $0,086 \mu$ moles $^{3} \mathrm{~L}^{-1}$, ajustada para $\mathrm{pH}$ 5,5 , e completada com água desionizada, quando necessário. A cada 15 dias, os vasos eram lavados com $5 \mathrm{~L}$ de água desionizada, após o que era adicionado $1,5 \mathrm{~L}$ de solução nutritiva a cada vaso.

Cinco (5) meses após o plantio (MAP) (março de 2000), o $\mathrm{B}$ foi suprimido da solução nutritiva de dez plantas e as outras dez continuaram recebendo a solução nutritiva completa.

Em maio de 2000, sete (7) MAP, induziram-se as plantas ao florescimento, com uma solução de Ethephon (50 ppm). Nesta época, as plantas apresentavam 25 a 30 folhas.

A colheita dos frutos se iniciou seis meses após a indução floral (novembro/dezembro de 2000), correspondendo a 13/14 MAP. A formação de mudas, tipo filhote-rebentão e rebentão foi acompanhada nestas plantas por quatro meses (março a junho de 2001).

No final de junho de 2001, a planta-mãe foi eliminada, deixando-se uma muda tipo rebentão basal em cada vaso (segunda safra ou soca), quando se iniciou o ensaio 1. Neste ensaio (cultivo da soca), 10 plantas continuaram recebendo solução com B (Tratamento 1) e 10, solução sem B (Tratamento 2).

As plantas-soca foram conduzidas com a mesma metodologia utilizada no primeiro ciclo de cultivo. As que não tiveram indução natural no inverno de 2001 foram induzidas artificialmente com solução de Ethephon aos sete meses após o início do ensaio e uma reaplicação foi feita dois meses após esta (março de 2002). A colheita dos frutos das plantas-soca induzidos naturalmente foi iniciada em março de 2002, sendo que esta se estendeu até agosto de 2002.

Ao longo do ciclo foi feito um acompanhamento dos teores de B, na folha "D". No laboratório, as folhas foram limpas com algodão umedecido em água desionizada e, depois, secas em estufa de circulação de ar forçada, a $70-75^{\circ} \mathrm{C}$, por 72 horas. Após secas, as amostras foram pesadas e moídas em moinho tipo Wiley, passadas em peneira de 30 mesh e armazenadas em frascos hermeticamente vedados.

O B foi determinado pelo método da Azometina-H e o seu teor foi expresso em $\mathrm{mg} \mathrm{kg}^{-1}$ na massa seca das porçōes da planta (Malavolta et al., 1997).

As avaliações dos sintomas visuais de deficiência de B foram feitas por descrição das alterações morfológicas decorrentes dessa deficiência.

\section{ENSAIO 2}

Vinte mudas do tipo rebentão basal, obtidas das plantasmãe cultivadas em areia no ensaio 1 , foram transferidas, em junho de 2001, para vasos plásticos com $15 \mathrm{~L}$ de capacidade, contendo solução nutritiva idêntica à utilizada no ensaio 1 . 
A correção do $\mathrm{pH}$ para 5,5 foi feita a cada dois dias e a troca da solução a cada 30 dias.

Dez mudas provenientes de plantas-mãe cultivadas com solução sem boro na areia continuaram a ser mantidas em solução nutritiva sem boro e as dez provenientes de plantasmãe cultivadas com boro continuaram a receber a solução com boro (solução completa do ensaio 1).

Duas determinações foliares de B foram feitas ao longo do ciclo vegetativo, aos 4 e 10 meses após o início do ensaio, outubro de 2001 e abril de 2002, respectivamente. As amostras consistiram da folha "D", folha basal e folha nova e a metodologia foi a mesma adotada no ensaio 1 .

\section{RESULTADOS E DISCUSSÃO}

\section{ENSAIO 1}

No primeiro ciclo de cultivo e antes do florescimento, os teores de $\mathrm{B}$ na folha " $\mathrm{D}$ " de plantas de abacaxi 'Pérola' (Tabela 1) estavam abaixo da faixa considerada adequada por Boaretto et al. (1999) (20-40 $\mathrm{mg} \mathrm{kg}^{-1}$ de massa seca) para o tratamento sem $B$ e no limite inferior para o tratamento com B. Apesar das diferenças nos teores de B, todas as plantas formaram frutos normais, sem que tivessem sido observados efeitos dos tratamentos com B em características qualitativas e quantitativas destes frutos (dados não apresentados).

As plantas cultivadas sem $B$ emitiram um número maior de mudas do tipo rebento durante os quatro meses de avaliação do que as plantas que receberam solução com B (Tabela 2). Entretanto, o número de mudas tipo rebentão basal não foi alterado pela deficiência de $\mathrm{B}$.

A maior formação de mudas do tipo rebento, nas plantas cultivadas sem $\mathrm{B}$, pode ser conseqüêencia dos baixos teores de $\mathrm{B}$ observados nestas plantas, nas quais o estresse interno induziria à antecipação da emissão de órgãos propagadores da espécie (Tabela 2).

No início (março de 2001), havia, em média, 0,85 mudas do tipo rebentão basal por planta-mãe e após 4 meses havia 2,55 mudas por planta (Tabela 2). Portanto, na formação de mudas dos dois tratamentos o fator tempo teve efeito significativo.

As mudas do tipo rebentão basal (plantas-soca), mantidas sem $B$ na solução, após a eliminação da planta-mãe, apresentaram um crescimento aparentemente normal ao longo do ciclo vegetativo. Aos quatro meses após o início do ensaio (Outubro de 2001), o teor de B na folha "D" destas plantas $\left(11 \mathrm{mg} \mathrm{kg}^{-1}\right)$ estava abaixo da faixa considerada adequada por Boaretto et al. (1999).

Ao comparar o teor de B $\left(11 \mathrm{mg} \mathrm{kg}^{-1}\right)$, na fase de crescimento vegetativo, das plantas-soca com os encontrados nas plantas no primeiro ciclo de cultivo (Tabela 1), principalmente para as plantas cultivadas sem $\mathrm{B}$ desde março de 2000, pôde-se observar que os teores encontrados na planta-soca são menores. A redução deste teor é decorrente do efeito de diluição, pois, mesmo com a retirada do $\mathrm{B}$ da solução, novos tecidos foram formados com o conteúdo do nutriente pré-existente na planta.

Ao iniciarem o crescimento reprodutivo, 3 das 20 plantassoca tiveram indução floral natural no inverno de 2001, uma delas do tratamento com B e duas do sem B, sendo que os frutos foram colhidos em março de 2002. As demais plantas foram induzidas artificialmente, mas algumas delas, mesmo recebendo duas aplicaçôes de Ethephon, não floresceram, e sim formaram um tufo de folhas (Fig. 1E e 1F).

Os frutos oriundos de plantas-soca induzidas naturalmente, cultivadas sem $\mathrm{B}$, apresentaram a formação de excrescências cortiçosas entre os frutilhos (Fig. 1A) e o fruto formado em plantas que receberam B na solução se apresentava normal, com a casca lisa entre os frutilhos.

As plantas que iniciaram a formação de frutos posteriormente, em função da indução artificial, apresentaram sintomas de deficiência de B mais intensos. Os frutos eram deformados, sem coroa e com rachaduras e excessiva formação de excrescências cortiçosas entre os frutilhos e nas rachaduras (Fig. 1B). Outros frutos apresentavam formação de pescoço (Fig. 1C).

Desta mesma época de floração, outras plantas não formaram o fruto e, sim, um aglomerado de tecido cortiçoso

Tabela 1 - Teores de B, no primeiro ciclo de cultivo, na porção clorofilada da folha "D" em plantas de abacaxi 'Pérola' cultivadas em vasos com areia, com ou sem B na solução nutritiva

\begin{tabular}{cll}
\hline Meses após o plantio* & Com Boro & Sem Boro \\
\hline 3 & 19,3 & \\
6 & 19,6 & 16,8 \\
$8^{1 /}$ & 23,4 & 10,7 \\
10 & 24,1 & 10,5 \\
\hline
\end{tabular}

${ }^{1}$ Início do período reprodutivo.

* Plantio: outubro de 1999.

Tabela 2 - Número de mudas tipo rebento e rebentão basal em plantas de abacaxi 'Pérola' cultivadas em vasos com e sem B*

\begin{tabular}{lllllll}
\hline \multirow{2}{*}{ Época } & \multicolumn{2}{l}{ Rebento } & \multicolumn{5}{l}{ Rebentão basal } \\
\cline { 2 - 7 } & Com B & Sem B & Médias & Com B & Sem B & Médias \\
\hline Mar. & 1,0 & 1,5 & $1,25 \mathrm{a}$ & 0,8 & 0,9 & $0,85 \mathrm{C}$ \\
Apr. & 1,0 & 1,5 & $1,25 \mathrm{a}$ & 1,6 & 1,5 & $1,55 \mathrm{~b}$ \\
Maio & 1,0 & 1,5 & $1,25 \mathrm{a}$ & 2,2 & 1,9 & $2,05 \mathrm{ab}$ \\
Jun. & 1,2 & 1,5 & $1,35 \mathrm{a}$ & 2,8 & 2,3 & $2,55 \mathrm{a}$ \\
Média & $1,05 \mathrm{~B}$ & $1,5 \mathrm{~A}$ & & $1,85 \mathrm{~A}$ & $1,65 \mathrm{~A}$ \\
\hline
\end{tabular}

Valores seguidos por letras maiúsculas (linha) e minúsculas (coluna) iguais não diferem entre si, pelo teste Tukey $(P>0,05)$ CV para rebento: 35,8\%; CV para rebentão basal: $44,1 \%$.

Acompanhamento iniciado em meados de fevereiro à final de junho de 2001, 
(Fig.1D). Em algumas dessas plantas ocorreu a formação de mudas, mas estas também apresentavam sintomas de deficiência de B, como: folhas coriáceas e menores do que as normais e com enrugamento do tecido foliar na região mediana da folha, provavelmente decorrente de falhas na estruturação da parede celular.

Malézieux \& Bartholomew (2003) relatam que em frutos jovens de plantas de abacaxi sob deficiência de B foi observada a ausência de tricomas, fazendo com que o fruto tivesse uma aparência lisa e brilhante. Estes eram menores com rachaduras entre os frutilhos onde houve a formação de excrescência corticosa. A ocorrência de rachaduras entre os frutilhos e a formação de excrescência corticosa e a deformação dos frutos de abacaxi de plantas do cultivar Imperial cultivados sob deficiência de B também foram observados por Ramos (2006)

Souza (1999) cita a formação de frutos pequenos e esféricos devido à deficiência de $\mathrm{B}$, o que também foi observado neste ensaio. Este autor ainda se refere à formação de frutos com coroas múltiplas em plantas deficientes. Com base nas observações deste ensaio com a cultivar Pérola, pode-se inferir que nas condições do experimento realizado a deficiência de B contribuiu para a formação de frutos "machos", ou seja, frutos sem coroa.

Os frutos atrofiados e com secreção de goma entre os frutilhos no final do ciclo, apresentaram uma alta infestação de cochonilhas e, provavelmente, de doenças secundárias, devido à presença de rachaduras entre os frutilhos.

Aquino et al. (1986), citados por Quaggio e Piza Jr. (2001), relatam que em deficiência extrema, devido à deterioração do sistema vascular, pode ocorrer a morte do meristema apical. Embora o teor de $\mathrm{B}$ das plantas submetidas à deficiência
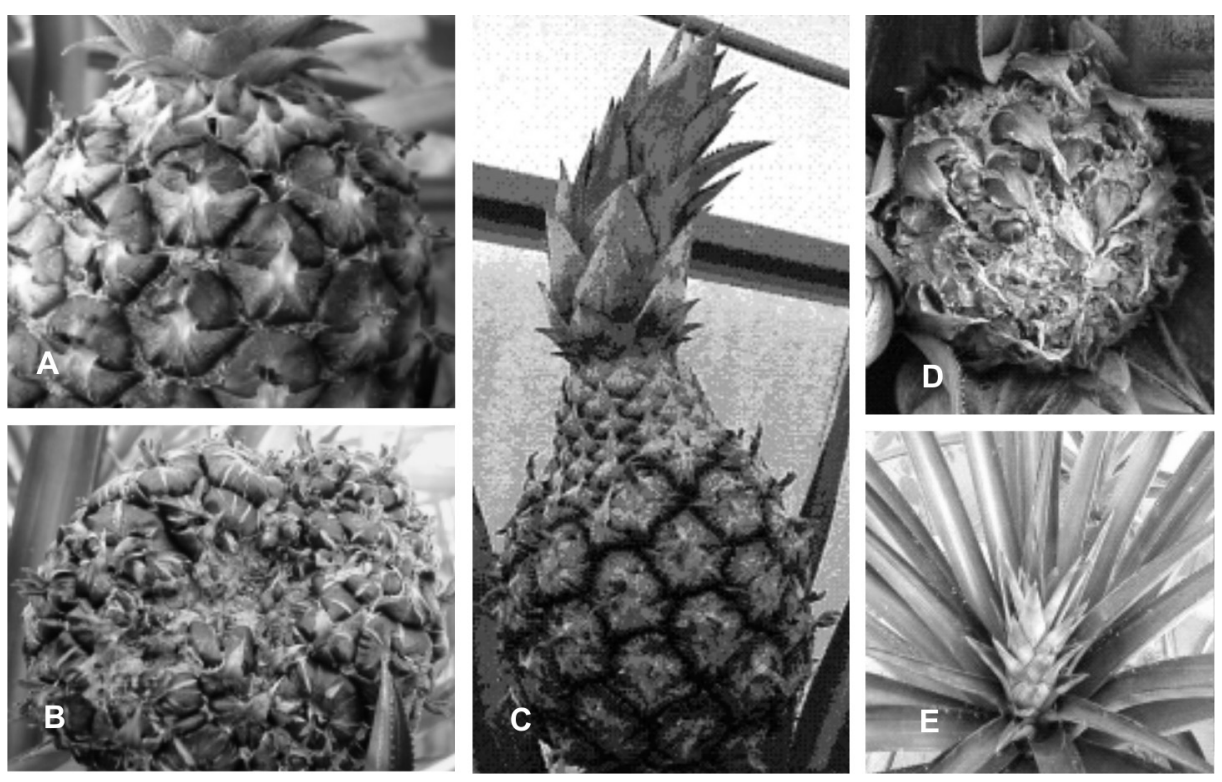

desse micronutriente tenha sido extremamente baixo antes do florescimento, não se constatou a morte do meristema apical nem o escurecimento dos tecidos vasculares no caule de plantas amostradas.

Nas plantas sob deficiência de B, as folhas formadas eram menores, com pontas secas e sua formação não era simétrica, como em plantas normais. Tais folhas se apresentavam coriáceas, espessas, podendo ou não ser retorcidas. Estes sintomas, citados também por Souza (1999), foram mais nítidos em plantas que não formaram fruto e nas folhas das mudas do tipo filhote (Fig.1E e 1F). Maléxieuz e Bartholomew (2003) também citam que folhas formadas em plantas sob deficiência de $\mathrm{B}$ eram menores e mais endurecidas do que as normais. Aquino et al. (1986), citados por Quaggio e Piza Jr. (2001), também observaram a formação de folhas coriáceas, espessas com cor natural e as folhas da roseta central retorcidas.

A deficiência de $\mathrm{B}$ nas folhas de abacaxizeiro é caracterizada por morte da ponta das folhas com eventual formação de margens serrilhadas e, em casos extremos, pode ocorrer a morte do meristema apical da planta (Maléxieuz e Bartholomew, 2003).

Nas folhas apicais e basais e no caule de mudas do tipo filhote das plantas-soca de abacaxi os teores de $\mathrm{B}$ variaram entre as plantas que apresentavam diferentes graus de deficiência de B (Tabela 3). As concentraçóes mais baixas deste nutriente foram observadas nas mudas provenientes das plantas com os sintomas de deficiência mais severos.

Nas partes das mudas do tipo filhote analisadas foi observada uma variação no teor de B (Tabela 3).Em mudas provenientes das plantas que apresentavam fruto com sintoma de deficiência de $\mathrm{B}$, a maior concentração de $\mathrm{B}$ foi observada

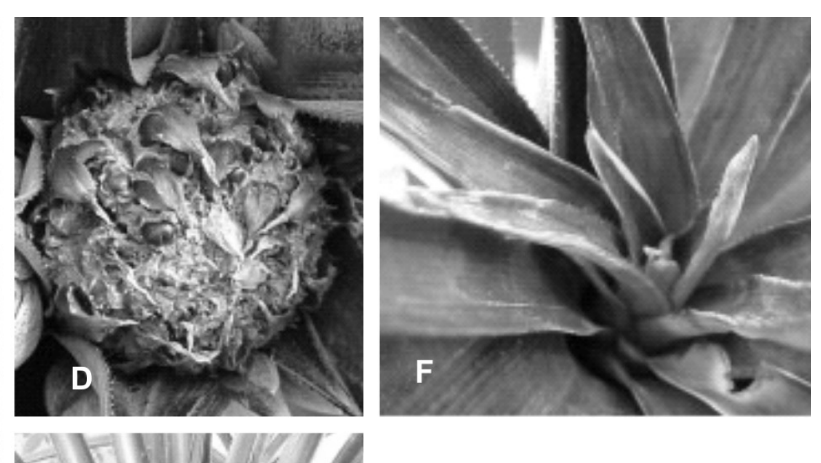

Figura 1 - A: Formação de excrescência corticosa e rachadura entre os frutilhos; B e D: Fruto totalmente deformado; C: formação de pescoço; E e F: Sintoma de deficiência de $B$ nas folhas. 
no caule e em plantas sem sintoma de deficiência a maior concentração foi observada nas folhas basais.

Assim, infere-se que o conteúdo de $\mathrm{B}$ já existente na muda e o fornecido no início do primeiro cultivo (out/1999 a $\mathrm{mar} / 2000$ ) foram suficientes para permitir o desenvolvimento da primeira frutificação sem sintomas de deficiência. Já, na planta-soca o teor de B era extremamente baixo (Tabela 3), logo, mesmo havendo a remobilização do $\mathrm{B}$, a quantidade redistribuída não foi suficiente para a formação de frutos e mudas normais.

\section{ENSAIO 2}

As mudas, tipo rebentão, cultivados em solução nutritiva sem B apresentaram um crescimento vegetativo normal, não havendo sinais visíveis de sua deficiência nas plantas. Aparentemente, o crescimento do sistema radicular das plantas submetidas à deficiência de $\mathrm{B}$ não diferiu do das plantas que receberam $\mathrm{B}$ e não foram observados sintomas de deficiência nas raízes. Para Epstein e Bloom (2006) a deficiência de B afetaria muito o sistema radicular das plantas e estas ficariam mais suscetíveis ao ataque de bactérias e de fungos, o que não foi observado neste ensaio.

Neste ensaio, as plantas submetidas à deficiência de B também não formaram órgãos reprodutivos normais. Os sintomas de deficiência observados foram similares aos observados no Ensaio 1, sendo que, visualmente, a intensidade dos sintomas foi menor. Possivelmente isto seja decorrente do maior volume de solução nutritiva disponível para a absorção na hidroponia em relação ao cultivo na areia. Logo, a quantidade de $\mathrm{B}$ contaminante também seria maior nesta solução, com conseqüente menor intensidade dos sintomas.

Outro fator que pode ter contribuído para a redução da intensidade do sintoma em plantas cultivadas em solução nutritiva, foi o aumento da taxa transpiratória das plantas cultivadas em casa de vegetação no período de condução do ensaio 2. O incremento da taxa transpiratória das plantas de abacaxi 'Pérola', decorrente das altas temperaturas observadas no cultivo protegido, aumenta a quantidade de B

Tabela 3 - Teor de B (mg kg-1na matéria seca) em mudas tipo filhote provenientes de plantas-soca de abacaxi 'Pérola' cultivadas em areia, com frutos sem sintoma e com sintomas visuais de deficiência de B. Os valores representam a média de 3 repetições

\begin{tabular}{lllll}
\hline $\begin{array}{l}\text { Intensidade do } \\
\text { sintoma }\end{array}$ & $\begin{array}{l}\text { Folhas } \\
\text { basais }\end{array}$ & $\begin{array}{l}\text { Folhas } \\
\text { apicais }\end{array}$ & Caule & Média \\
\hline Sem sintoma & $18,9 \mathrm{Aa}$ & $14,5 \mathrm{Ca}$ & $17,0 \mathrm{Ba}$ & 16,8 \\
Leve & $4,2 \mathrm{Cb}$ & $6,4 \mathrm{Bb}$ & $8,9 \mathrm{Ab}$ & 6,5 \\
Severa & $3,0 \mathrm{Bb}$ & $4,1 \mathrm{ABc}$ & $5,8 \mathrm{Ac}$ & 4,3 \\
Média & 8,7 & 8,3 & 10,5 &
\end{tabular}

Valores seguidos por letras maiúsculas (linha) e minúsculas (coluna) iguais não diferem entre si, pelo teste Tukey $(P>0,05)$

Cv: $9,56 \%$. contaminante transportado para os órgãos novos das plantas cultivadas sem $B$ na solução nutritiva.

A deficiência de $B$ na solução nutritiva reduziu significativamente o teor desse micronutriente nos três tipos de folhas amostradas (Tabela 4).

Os teores de B nas folhas das plantas adequadamente supridas desse micronutriente aumentaram com a idade da planta, ao passo que diminuíram nas plantas que não receberam B na solução (Tabela 4).

Neste ensaio também foi observado o efeito de diluição, sendo que a quantidade de B nas plantas sob deficiência foi redistribuída dentro da planta, ocorrendo a redução do seu teor na segunda amostragem (Tabela 4).

Segundo Maléxieuz e Bartholomew (2003) o sintoma de deficiência no fruto foi associado com teores menores do que $0,4 \mathrm{mg} \mathrm{kg}^{-1} \mathrm{em}$ massa verde da maior folha da coroa do fruto 4,5 meses após a indução.

Em plantas de abacaxi que apresentavam suficiência de B, o teor deste micronutriente variou entre as diferentes folhas, sendo que o maior teor foi observado nas folhas mais velhas e o menor nas folhas mais novas. Já, nas plantas cultivadas sob deficiência de $\mathrm{B}$, não se constatou esta variação (Tabela 4). Este resultado novamente demonstra a remobilização do $\mathrm{B}$ das folhas mais velhas para os tecidos mais novos, quando a planta de abacaxi se encontra em meio deficiente de B. O mesmo foi sugerido por Siebeneichler et al. (2005).

\section{CONCLUSÕES}

Em plantas de abacaxi 'Pérola' cultivadas em solução nutritiva, os sintomas de deficiência de B foram observados somente no segundo ciclo reprodutivo.

O boro foi remobilizado dentro da planta de abacaxi 'Pérola'.

Os sintomas de deficiência de B se caracterizaram por frutos deformados e menores, com excrescências cortiçosas entre os frutilhos. As mudas formadas apresentaram a borda

Tabela 4: Teor de B (mg kg-1 na matéria seca) na porção clorofilada de folhas novas, "D" e velhas de plantas de abacaxi 'Pérola' cultivadas em solução nutritiva com e sem B em duas épocas (4 e 10 meses após o início do ensaio)

\begin{tabular}{llllll}
\hline & & Folha Nova & Folha "D" & Folha Velha & Média \\
\hline \multirow{2}{*}{ Com } & 4 meses & 14,3 & 20,1 & 32,3 & $22,2 \mathrm{Aa}$ \\
Boro & 10 meses & 18,6 & 26,3 & 38,5 & $27,8 \mathrm{Aa}$ \\
& Média & $16,5 \mathrm{cA}$ & $23,2 \mathrm{bA}$ & $35,4 \mathrm{aA}$ & \\
\multirow{2}{*}{ Sem } & 4 meses & 11,7 & 11,4 & 12,9 & $12,0 \mathrm{Ba}$ \\
Boro & 10 meses & 4,6 & 4,2 & 5,7 & $4,9 \mathrm{Bb}$ \\
& Média & $8,1 \mathrm{aB}$ & $7,8 \mathrm{aB}$ & $9,3 \mathrm{aB}$ & \\
\hline
\end{tabular}

Valores seguidos por letras maiúsculas iguais, entre os tratamentos com e sem $B$, não diferem entre si, pelo teste de Tukey $(P>0,05)$. As médias seguidas por letras minúsculas iguais, na comparacão entre idade de folha e da planta, não diferem entre si, pelo teste de Tukey $(P>0,05)$. 
das folhas irregulares, com pontas secas e as folhas mais novas retorcidas ou não. Além disso, os frutos formados apresentavam uma única coroa ou não apresentavam a formação de coroa.

\section{BIBLIOGRAFIA CITADA}

Boaretto, A.E., Chitolina, J.C., Raij, B.van, Silva, F.C. da, Tedesco, M.J., Carmo, C.A.F. de S. do. 1999. Amostragem, acondicionamento e preparação das amostras de plantas para análise química. In: Silva, F.C. da. (Org.) Manual de análises quimicas de solos, plantas e fertilizantes. Brasília: Embrapa Comunicação para Transferência de Tecnologia. p.:49-74.

Epstein, E. \& Bloom, A.J. 2006. Nutrição mineral de plantas, princípios eperspectivas. Trad. Maria Edna Tenório Nunes. Editora Planta, Londrina, PR. 403pp.

Malézieux, E.; Bartholomew, D.P. 2003. Plant Nutrition. In: Bartholomew, D.P.; Paull, R.E.; Rohrbach, K.G. (Eds.) The pineapple: Botany, Production and Uses. CABI Publishing, Honolulu, USA. P.: 143-165.

Malavolta, E., Vitti, G.C., Oliveira, S.A. de. 1997. Avaliação do estado nutricional das plantas: princípios e aplicaçôes, 2. ed. Piracicaba: POTAFOS. 319 pp.
Marschner, H. 1995. Mineral Nutrition of Higher Plants. 2.ed. Ed. London: Academic Press., 675pp.

Quaggio, J.A.; Piza JR., C. de T. 2001. Fruteiras tropicais. In: Ferreira, M.E., Cruz, M.C.P. da, Raij, B.van, Abreu, C.A. de (eds.) Micronutrientes e elementos tóxicos na agricultura. Jaboticabal: Legis Summa Ltda. p.: 43-70.

Ramos, M.J.M. 2006. Caracterização de sintomas de deficiência de macronutrientes e boro em abacaxizeiro cultivar Imperial. Tese de doutorado, Centro de Ciências e Tecnologias Agropecuárias/ Universidade Estadual do Norte Fluminense Darcy Ribeiro, Campos dos Goytacazes, RJ. 96 pp.

Siebeneichler, S.C.; Monnerat, P.H.; Carvalho, A.J.C. de; Silva, J.A. da; Martins, A.O. 2005. Mobilidade do boro em plantas de abacaxi. Revista Brasileira de Fruticultura, 27 (2): 292-294

Souza, L.F. da S. 1999. Exigências edáficas e nutricionais. In: Cunha, G.A.P. da, Cabral, J.R.S., Souza, L.F. da S.(org.) O abacaxizeiro. Cultivo, agroinduistria e economia.: Embrapa Comunicação para Transferência de Tecnologia, Brasília, DF. p.:67-77.

Recebido em 31/12/2007

Aceito em 02/08/2008 